\title{
Association between education and television viewing among older working and retired people: a comparative study of Finland and Japan
}

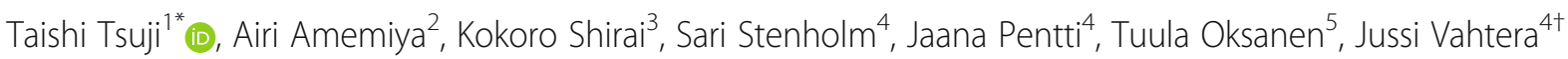
and Katsunori Kondo ${ }^{1,6+}$

\begin{abstract}
Background: Educational attainment is associated with physical activity among older people. However, little is known about its association with sedentary lifestyle in European as well as Asian nations. This study aims to examine the associations between educational attainment and daily television viewing as an indicator of a sedentary lifestyle among older working and retired people in Finland and Japan.
\end{abstract}

Methods: We used cross-sectional harmonized data from two cohorts, the Finnish Public Sector study $(n=10,744)$ and the Japan Gerontological Evaluation Study ( $n=2493)$, evaluating individuals aged $65-75$ years old. We defined high-duration television viewing as $\geq 4 \mathrm{~h}$ per day. Poisson regression was used to examine the association between educational attainment and high-duration television viewing, stratified by the current working status. Models were adjusted for age, sex, household size, smoking, alcohol, body mass index, chronic diseases, mental disorders, and physical activity.

Results: Of the participants, 27\% in Finland and 30\% in Japan reported high-duration television viewing. Compared with a low education ( $\leq 9$ years), Finnish and Japanese retirees with a high education ( $\geq 13$ years) had less high-duration television viewing [prevalence ratio, PR 0.68 (95\% confidence interval 0.63-0.73) and 0.66 (0.55-0.79), respectively]. The corresponding PRs for Finnish and Japanese retirees with intermediate education were also lowered [0.89 (0.83-0.95) and 0.79 (0.68-0.91), respectively]. Among older people still at work, educational attainment was associated with high-duration television viewing among the Japanese but not among the Finnish.

Conclusion: A similar association between educational attainment and high-duration television viewing in Finland and Japan particularly after retirement suggests a robust and consistent impact of educational attainment on a sedentary lifestyle after retirements.

Keywords: Television watching, Sedentariness, Elderly, Work status, Retirement

\footnotetext{
* Correspondence: tsuji.t@chiba-u.jp

†ussi Vahtera and Katsunori Kondo contributed equally to this work.

${ }^{1}$ Center for Preventive Medical Sciences, Chiba University, 1-8-1 Inohana,

Chuo Ward, Chiba City, Chiba, Japan

Full list of author information is available at the end of the article
}

(c) The Author(s). 2018 Open Access This article is distributed under the terms of the Creative Commons Attribution 4.0 International License (http://creativecommons.org/licenses/by/4.0/), which permits unrestricted use, distribution, and reproduction in any medium, provided you give appropriate credit to the original author(s) and the source, provide a link to the Creative Commons license, and indicate if changes were made. The Creative Commons Public Domain Dedication waiver (http://creativecommons.org/publicdomain/zero/1.0/) applies to the data made available in this article, unless otherwise stated. 


\section{Background}

Longer duration of television (TV) viewing, a correlate of a sedentary lifestyle, is associated with an increased risk of adverse health outcomes, such as obesity [1-3], diabetes $[3,4]$, cardiovascular disease $[5,6]$, cancer $[7,8]$, and mortality $[6,9]$. The potential mechanisms for the adverse relationship between TV viewing and health outcomes include reduced energy expenditure compared with other sedentary activities, such as reading and driving a car, and an increased food and total energy intake while viewing TV [3]. Compared with younger or middle-aged people, the duration of TV viewing tends to increase with age in older people, particularly after retirement [10]. The daily TV viewing duration has been found to be approximately 50 min longer for people aged 65-74 years compared with those aged 55-64 years and was approximately $2 \mathrm{~h}$ longer for unemployed people compared with full-time workers of this age [11]. This further suggests that this behavioral change poses an additional threat to health of older people. Therefore, high-duration TV viewing could be used as a screening tool to identify susceptible groups for timely interventions.

Several studies have shown that older people with a high socioeconomic status (SES) have a higher level of leisure-time physical activity (PA) and exercise more than the older people with a lower SES [12, 13]. To measure the SES of older people, educational attainment, which is normally fixed earlier in life than occupational class or income, is often regarded as a first-choice indicator because problems of reverse causation are much less serious $[14,15]$. Murakami and colleagues reported that older individuals who have a higher educational attainment are more likely to have higher levels of PA [12]. A sedentary lifestyle, however, is not exclusive from leisure-time PA and may have adverse effects on health outcomes independently from leisure-time PA [3, 16]. Therefore, the determinants of PA and sedentary lifestyle are not necessarily the same. Although some previous studies have reported that a low SES may have an adverse effect on a sedentary lifestyle among youth [17] and adults (partially including older people) [1820], there is little evidence of the social determinants of a sedentary lifestyle focusing on older people irrespective of nationality or cultural background [21, 22]. Therefore, this study aimed to examine the association between educational attainment and sedentary lifestyle evaluated by the high duration of TV viewing among older working and retired people. Furthermore, we investigated the association in both Finland, one of the nations with the highest level of welfare, and Japan, the nation with the world's highest proportion of older people, to clarify whether a universal relationship exists between two nations' older populations with different races and cultural backgrounds.

\section{Methods \\ Sample}

We collected data from surveys conducted among older people in Finland and Japan. The Finnish data were derived from the Finnish Public Sector (FPS) cohort study. FPS study participants were employees representing a wide range of occupations working in 10 towns and six hospital districts. The data used in this study was restricted to participants aged 65-75 who responded to the 2013 survey inquiring information on duration of TV viewing $[n=10,744$, response rate $=65 \%(24,679 / 38,230)]$.

The Japanese data were obtained from the Japan Gerontological Evaluation Study (JAGES), a population-based, cross-sectional study of individuals aged 65 years or older without disability from 31 municipalities, which was conducted between August 2010 and January 2012 ( $n=$ 112,123; response rate $=66.3 \%$ ) [23]. The data used in the present study were from a sub-sample of the JAGES participants residing in the cities of Kashiwa, Nagoya, and Kobe, of which one-fifth provided information on the duration of TV viewing $(n=5360)$. Participants aged 76 years or older $(n=2037)$ were excluded to harmonize with the FPS samples' age range. In addition, we excluded 556 participants whose status of TV viewing, educational attainment, or current working status were unknown, and 274 participants never had a job. The studies included a total of 2493 (1336 men and 1157 women) participants from Japan and 10,744 (2199 men and 8545 women) participants from Finland.

\section{Measurement of the duration of TV viewing}

In the FPS study, the duration of daily TV viewing was assessed with the following question: "For how many hours do you sit while watching TV/video every day?" In the JAGES, the duration was assessed with the following question: "How much television (including videos) do you watch in a day on average?" Response options were $<1 \mathrm{~h}, 1-2 \mathrm{~h}, 2-3 \mathrm{~h}, 3-4 \mathrm{~h}$, and $\geq 4 \mathrm{~h}$ in both questions. We categorized $\geq 4 \mathrm{~h}$ into "high-duration" of TV viewing on the basis that the threshold elevated the risk of all-cause and cardiovascular disease mortality [24].

\section{Measurement of educational attainment}

Educational attainment was categorized into three levels: (i) $\leq 9$ years, i.e., comprehensive school (Finland) and junior high school (Japan); (ii) 10-12 years, i.e., post-compulsory secondary general academic and vocational education (Finland) and high school and technical college (Japan); and (iii) $\geq 13$ years, i.e., university degree.

\section{Current working status}

In the FPS study, a survey response to a question "What is your current working status?" was used. Participants who answered "working full-time" or "part-time" were classified 
as workers $(n=699)$, and those who answered "retired" ( $n=10,010)$ or "not working from other causes" $(n=35)$ were classified as retired. In the JAGES, the participants were asked "What is your current working status?" Those who answered "having a paid job" were classified as workers $(n=739)$, and those who answered "retired" were classified as retired $(n=1754)$. Those who answered "never had a job" were excluded from the analysis $(n=274)$.

\section{Covariates}

Other covariates were age (continuous), sex, household size (1, 2, or $\geq 3$ individuals), smoking (never, former, or current smoker), alcohol consumption (non-drinker or current drinker), chronic diseases (having one or more of the following diseases: cancer, cardiovascular diseases, stroke, and diabetes mellitus), mental disorders (a score of $\geq 4$ in the 12-Item General Health Questionnaire [25] in the FPS study and a score of $\geq 11$ in the Geriatric Depression Scale $[26,27]$ in the JAGES), and moderate/vigorous PA ( $<1$ day per week or $\geq 1$ day per week). In the FPS study, the participants were asked about their average weekly hours of leisure-time PA (including commuting) within the previous year spent walking, brisk walking, jogging, and running, or their equivalent activities. The participants were classified based on whether they performed brisk walking (and equivalent) or a higher intensity of PA for $1 \mathrm{~h}$ per week or longer. In the JAGES, the participants were asked about their frequency of low-, middle-, and high-intensity PA and were classified based on whether middle- and/or high-intensity PA was practiced at least once a week or less than once a week. Body mass index (BMI) was calculated as the self-reported weight divided by the square of the self-reported height and then categorized as $<18.5$, 18.5-24.9, 25-29.9, and $\geq 30$. Missing values were treated as dummy variables.

\section{Statistical analysis}

A Poisson regression analysis stratified by the current working status was performed to examine the effect of educational attainment on the duration of TV viewing. Model 1 was adjusted for age and sex. Model 2 was adjusted for smoking, alcohol consumption, BMI, household size, chronic diseases, and mental disorders. Model 3 was further adjusted for moderate/vigorous PA. Prevalence ratios (PRs) and their 95\% confidence intervals (95\% CIs) were calculated. We also conducted sensitivity analyses with outcomes set to cut points of $\geq 3 \mathrm{~h}$ and $\geq 2 \mathrm{~h}$ per day for high-duration TV viewing. Statistical analysis was performed using the SAS statistical software, version 9.1.3 (SAS Institute, Inc., Cary, North Carolina) and IBM SPSS Statistics 22 (IBM Corp. Armonk, New York).

\section{Results}

Table 1 shows the descriptive cohort-specific data of the participants combined and by their working status. In the Japanese study, $46 \%$ were women compared with $80 \%$ in the Finnish study. The proportion of moderate/vigorous PA one day per week or more was higher in Finland than in Japan. The prevalence of high-duration TV viewing was somewhat lower in Finland (27\%) than in Japan (30\%). Retired participants had a high-duration TV viewing more frequently than those still working in both countries (Finland: $28 \%$ vs. $16 \%$; Japan: $34 \%$ vs. $19 \%$ ).

Table 2 shows the association between educational attainment and high-duration TV viewing by the working status for each cohort. In both cohorts, irrespective of the working status, the level of education was inversely associated with unadjusted values for high-duration TV viewing. After adjusting for all covariates, the associations attenuated but remained significant with one exception, the FPS participants were still working. The fully adjusted prevalence compared with those with a low education was 0.68 -fold (95\% CI: 0.63-0.73) for high and 0.89 -fold (0.83-0.95) for intermediate education among retired FPS cohort members. The corresponding PRs for retired JAGES cohort members were 0.66 (0.550.79 ) and 0.79 (0.68-0.91), respectively. Among working JAGES cohort members with high education compared with low education, the prevalence of high-duration TV time was almost the same than that among the retirees, in which the fully adjusted prevalence was 0.63-fold (0.42-0.93). An additional table presents the results of the sensitivity analyses with outcomes set to TV viewing durations of $\geq 3 \mathrm{~h}$ and $\geq 2 \mathrm{~h}$ per day (see Additional file 1 ). A similar, albeit marginally weaker tendency of the relationship was observed for these lower cut points for high-duration TV viewing.

\section{Discussion}

The present study found that educational attainment is similarly associated with the duration of TV viewing among older people after retirement in Finland and Japan, which suggests the robust and consistent positive impact of higher educational attainment on avoiding a sedentary lifestyle among those who have retired from their job. This association was found to exist independently of moderate/vigorous PA. Furthermore, the association was also significant among the older current workers in Japan; however, it was not significant among that subgroup in Finland.

Our results regarding retired populations are in line with those of earlier reports indicating a significant association between high education and habitual exercise in older people [12]. Even if the assumed confounders and mediators were adjusted in the present study, the strength of the association between educational attainment and 
Table 1 Descriptive data of participants for each cohort and each current working status

\begin{tabular}{|c|c|c|c|c|c|c|c|c|c|c|c|c|}
\hline \multirow{4}{*}{ Daily TV viewing $(n, \%)$} & \multicolumn{6}{|c|}{ Finland } & \multicolumn{6}{|l|}{ Japan } \\
\hline & \multicolumn{2}{|l|}{ Total } & \multicolumn{2}{|c|}{ Working } & \multicolumn{2}{|c|}{ Retired } & \multicolumn{2}{|l|}{ Total } & \multicolumn{2}{|c|}{ Working } & \multicolumn{2}{|c|}{ Retired } \\
\hline & \multicolumn{2}{|c|}{$(n=10,744)$} & \multicolumn{2}{|c|}{$(n=699)$} & \multicolumn{2}{|c|}{$(n=10,045)$} & \multicolumn{2}{|c|}{$(n=2,493)$} & \multicolumn{2}{|c|}{$(n=739)$} & \multicolumn{2}{|c|}{$(n=1,754)$} \\
\hline & & & & & & & & & & & & \\
\hline$<2$ hours & 1,309 & $12.2 \%$ & 156 & $22.3 \%$ & 1,153 & $11.5 \%$ & 455 & $18.3 \%$ & 183 & $24.8 \%$ & 272 & $15.5 \%$ \\
\hline $2-<3$ hours & 3,148 & $29.3 \%$ & 261 & $37.3 \%$ & 2,887 & $28.7 \%$ & 627 & $25.2 \%$ & 221 & $29.9 \%$ & 406 & $23.1 \%$ \\
\hline $3-<4$ hours & 3,392 & $31.6 \%$ & 173 & $24.7 \%$ & 3,219 & $32.0 \%$ & 672 & $27.0 \%$ & 198 & $26.8 \%$ & 474 & $27.0 \%$ \\
\hline$\geq 4$ hours & 2,895 & $26.9 \%$ & 109 & $15.6 \%$ & 2,786 & $27.7 \%$ & 739 & $29.6 \%$ & 137 & $18.5 \%$ & 602 & $34.3 \%$ \\
\hline \multicolumn{13}{|l|}{ Education (n, \%) } \\
\hline Low: $\leq 9$ years & 1,958 & $18.2 \%$ & 65 & $9.3 \%$ & 1,893 & $18.8 \%$ & 683 & $27.4 \%$ & 217 & $29.4 \%$ & 466 & $26.6 \%$ \\
\hline Middle: $10-12$ years & 3,362 & $31.3 \%$ & 180 & $25.8 \%$ & 3,182 & $31.7 \%$ & 1,031 & $41.4 \%$ & 276 & $37.3 \%$ & 755 & $43.0 \%$ \\
\hline High: $\geq 13$ years & 5,424 & $50.5 \%$ & 454 & $64.9 \%$ & 4,970 & $49.5 \%$ & 779 & $31.2 \%$ & 246 & $33.3 \%$ & 533 & $30.4 \%$ \\
\hline \multicolumn{13}{|l|}{ Age (mean, SD) } \\
\hline Years & 68.5 & 2.6 & 67.4 & 2.3 & 68.5 & 2.7 & 70.1 & 2.8 & 69.5 & 2.7 & 70.4 & 2.8 \\
\hline \multicolumn{13}{|l|}{$\operatorname{Sex}(n, \%)$} \\
\hline Men & 2,199 & $20.5 \%$ & 197 & $28.2 \%$ & 2,002 & $19.9 \%$ & 1,336 & $53.6 \%$ & 457 & $61.8 \%$ & 879 & $50.1 \%$ \\
\hline Women & 8,545 & $79.5 \%$ & 502 & $71.8 \%$ & 8,043 & $80.1 \%$ & 1,157 & $46.4 \%$ & 282 & $38.2 \%$ & 875 & $49.9 \%$ \\
\hline \multicolumn{13}{|l|}{ Household size (n, \%) } \\
\hline 1 person & 3,590 & $33.4 \%$ & 278 & $39.8 \%$ & 3,312 & $33.0 \%$ & 371 & $14.9 \%$ & 102 & $13.8 \%$ & 269 & $15.3 \%$ \\
\hline 2 people & 6,385 & $59.4 \%$ & 372 & $53.2 \%$ & 6,013 & $59.9 \%$ & 1,260 & $50.5 \%$ & 345 & $46.7 \%$ & 915 & $52.2 \%$ \\
\hline$\geq 3$ people & 244 & $2.3 \%$ & 27 & $3.9 \%$ & 217 & $2.2 \%$ & 763 & $30.6 \%$ & 263 & $35.6 \%$ & 500 & $28.5 \%$ \\
\hline Missing & 525 & $4.9 \%$ & 22 & $3.1 \%$ & 503 & $5.0 \%$ & 99 & $4.0 \%$ & 29 & $3.9 \%$ & 70 & $4.0 \%$ \\
\hline \multicolumn{13}{|l|}{ Body mass index (n, \%) } \\
\hline$<18.5 \mathrm{~kg} / \mathrm{m}^{2}$ & 99 & $0.9 \%$ & 3 & $0.4 \%$ & 96 & $1.0 \%$ & 149 & $6.0 \%$ & 36 & $4.9 \%$ & 113 & $6.4 \%$ \\
\hline $18.5-24.9 \mathrm{~kg} / \mathrm{m}^{2}$ & 4,071 & $37.9 \%$ & 272 & $38.9 \%$ & 3,799 & $37.8 \%$ & 1,805 & $72.4 \%$ & 534 & $72.3 \%$ & 1,271 & $72.5 \%$ \\
\hline $25.0-29.9 \mathrm{~kg} / \mathrm{m}^{2}$ & 4,091 & $38.1 \%$ & 291 & $41.6 \%$ & 3,800 & $37.8 \%$ & 454 & $18.2 \%$ & 148 & $20.0 \%$ & 306 & $17.4 \%$ \\
\hline$\geq 30.0 \mathrm{~kg} / \mathrm{m}^{2}$ & 1,949 & $18.1 \%$ & 109 & $15.6 \%$ & 1,840 & $18.3 \%$ & 44 & $1.8 \%$ & 14 & $1.9 \%$ & 30 & $1.7 \%$ \\
\hline Missing & 534 & $5.0 \%$ & 24 & $3.4 \%$ & 510 & $5.1 \%$ & 41 & $1.6 \%$ & 7 & $0.9 \%$ & 34 & $1.9 \%$ \\
\hline \multicolumn{13}{|l|}{ Smoking (n, \%) } \\
\hline Never & 7,986 & $74.3 \%$ & 510 & $73.0 \%$ & 7,476 & $74.4 \%$ & 1,155 & $46.3 \%$ & 328 & $44.4 \%$ & 827 & $47.1 \%$ \\
\hline Former & 2,022 & $18.8 \%$ & 133 & $19.0 \%$ & 1,889 & $18.8 \%$ & 802 & $32.2 \%$ & 251 & $34.0 \%$ & 551 & $31.4 \%$ \\
\hline Current & 694 & $6.5 \%$ & 55 & $7.9 \%$ & 639 & $6.4 \%$ & 338 & $13.6 \%$ & 109 & $14.7 \%$ & 229 & $13.1 \%$ \\
\hline Missing & 42 & $0.4 \%$ & 1 & $0.1 \%$ & 41 & $0.4 \%$ & 198 & $7.9 \%$ & 51 & $6.9 \%$ & 147 & $8.4 \%$ \\
\hline \multicolumn{13}{|l|}{ Alcohol (n, \%) } \\
\hline Non-drinker & 2,265 & $21.1 \%$ & 128 & $18.3 \%$ & 2,137 & $21.3 \%$ & 1,195 & $47.9 \%$ & 316 & $42.8 \%$ & 879 & $50.1 \%$ \\
\hline Drinker & 8,452 & $78.7 \%$ & 569 & $81.4 \%$ & 7,883 & $78.5 \%$ & 1,129 & $45.3 \%$ & 380 & $51.4 \%$ & 749 & $42.7 \%$ \\
\hline Missing & 27 & $0.3 \%$ & 2 & $0.3 \%$ & 25 & $0.2 \%$ & 169 & $6.8 \%$ & 43 & $5.8 \%$ & 126 & $7.2 \%$ \\
\hline Current chronic disease & $\%)$ & & & & & & & & & & & \\
\hline No & 7,397 & $68.8 \%$ & 523 & $74.8 \%$ & 6,874 & $68.4 \%$ & 1,215 & $48.7 \%$ & 363 & $49.1 \%$ & 852 & $48.6 \%$ \\
\hline Yes & 3,266 & $30.4 \%$ & 174 & $24.9 \%$ & 3,092 & $30.8 \%$ & 590 & $23.7 \%$ & 148 & $20.0 \%$ & 442 & $25.2 \%$ \\
\hline Missing & 81 & $0.8 \%$ & 2 & $0.3 \%$ & 79 & $0.8 \%$ & 688 & $27.6 \%$ & 228 & $30.9 \%$ & 460 & $26.2 \%$ \\
\hline
\end{tabular}


Table 1 Descriptive data of participants for each cohort and each current working status (Continued)

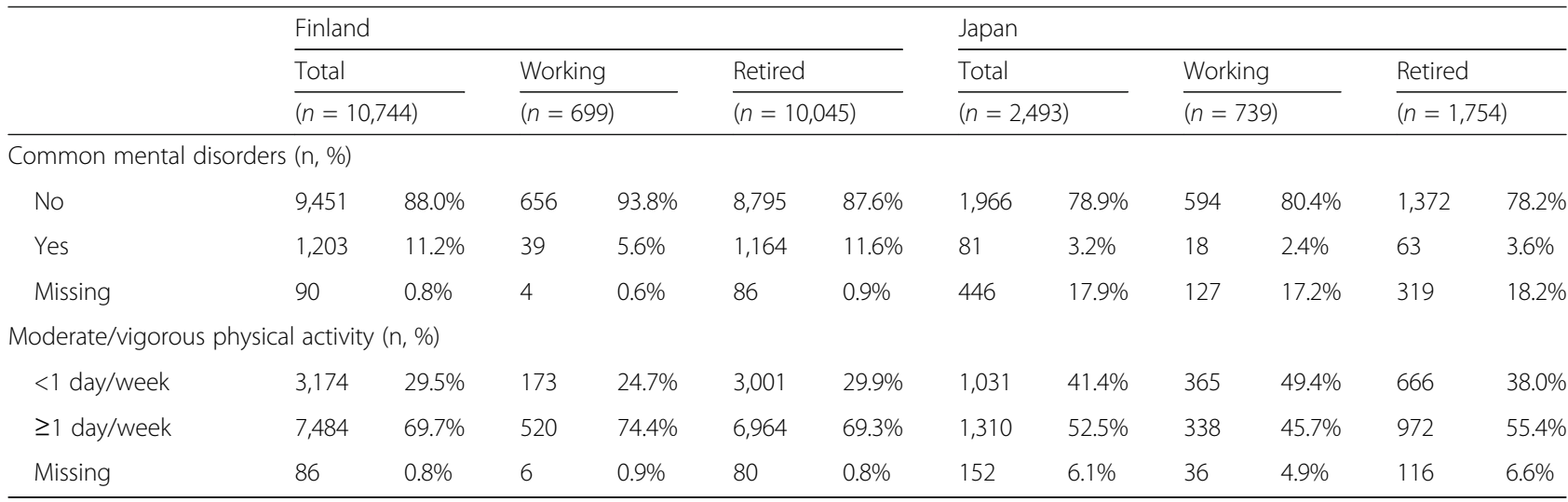

duration of daily TV viewing hardly changed among those older people who no longer work. Income, factual knowledge, enduring cognitive or emotional skills, and social network are regarded as mechanisms that link education to health behaviors and health outcomes [28]. Another possibility is that individuals with a higher education have a good pension which enables them to engage in various leisure-time activities, which require expenditure of money rather than TV viewing, an option less likely for those with a low education and smaller pension. Thus, a high duration of TV viewing would be among the pathways maintaining inequalities in health among older people.

Among older people still working, educational attainment was associated with high-duration TV viewing only in Japan, whereas among retirees, a similar inverse association was observed in both countries. Thus, cultural backgrounds such as those between Finland and Japan, may lead to different pathways through which education

Table 2 Association between educational attainment and high-duration of TV viewing for each cohort and each current working status

\begin{tabular}{|c|c|c|c|c|c|c|c|c|}
\hline & \multicolumn{2}{|c|}{ Crude model } & \multicolumn{2}{|c|}{ Model 1} & \multicolumn{2}{|c|}{ Model 2} & \multicolumn{2}{|c|}{ Model 3} \\
\hline & PR & $95 \% \mathrm{Cl}$ & PR & $95 \% \mathrm{Cl}$ & PR & $95 \% \mathrm{Cl}$ & PR & $95 \% \mathrm{Cl}$ \\
\hline \multicolumn{9}{|l|}{ Finland } \\
\hline \multicolumn{9}{|l|}{ Working $(n=699)$} \\
\hline Low: $\leq 9$ years & 1.00 & ref. & 1.00 & ref. & 1.00 & ref. & 1.00 & ref. \\
\hline Middle: 10-12 years & 0.87 & $(0.51-1.47)$ & 0.90 & $(0.52-1.54)$ & 0.93 & $(0.55-1.55)$ & 0.96 & $(0.56-1.62)$ \\
\hline High: $\geq 13$ years & 0.55 & $(0.33-0.92)$ & 0.59 & $(0.36-0.98)$ & 0.77 & $(0.47-1.26)$ & 0.78 & $(0.47-1.29)$ \\
\hline \multicolumn{9}{|l|}{ Retired $(n=10,045)$} \\
\hline Low: $\leq 9$ years & 1.00 & ref. & 1.00 & ref. & 1.00 & ref. & 1.00 & ref. \\
\hline Middle: 10-12 years & 0.82 & $(0.76-0.88)$ & 0.83 & $(0.77-0.90)$ & 0.89 & $(0.82-0.95)$ & 0.89 & $(0.83-0.95)$ \\
\hline High: $\geq 13$ years & 0.54 & $(0.50-0.58)$ & 0.54 & $(0.50-0.59)$ & 0.67 & $(0.62-0.72)$ & 0.68 & $(0.63-0.73)$ \\
\hline \multicolumn{9}{|l|}{ Japan } \\
\hline \multicolumn{9}{|l|}{ Working $(n=739)$} \\
\hline Low: $\leq 9$ years & 1.00 & ref. & 1.00 & ref. & 1.00 & ref. & 1.00 & ref. \\
\hline Middle: $10-12$ years & 0.77 & $(0.54-1.09)$ & 0.74 & $(0.53-1.05)$ & 0.73 & $(0.51-1.03)$ & 0.75 & $(0.53-1.06)$ \\
\hline High: $\geq 13$ years & 0.62 & $(0.42-0.92)$ & 0.62 & $(0.42-0.92)$ & 0.61 & $(0.41-0.91)$ & 0.63 & $(0.42-0.93)$ \\
\hline \multicolumn{9}{|l|}{ Retired $(n=1754)$} \\
\hline Low: $\leq 9$ years & 1.00 & ref. & 1.00 & ref. & 1.00 & ref. & 1.00 & ref. \\
\hline Middle: $10-12$ years & 0.76 & $(0.66-0.88)$ & 0.75 & $(0.65-0.87)$ & 0.77 & $(0.67-0.89)$ & 0.79 & $(0.68-0.91)$ \\
\hline High: $\geq 13$ years & 0.63 & $(0.53-0.74)$ & 0.61 & $(0.51-0.73)$ & 0.64 & $(0.54-0.77)$ & 0.66 & $(0.55-0.79)$ \\
\hline
\end{tabular}

PR: prevalence ratio, $\mathrm{Cl}$ : confidence interval

Model 1: crude model + age and sex

Model 2: model 1 + household size, smoking, alcohol, body mass index, current chronic disease, and common mental disorders

Model 3: model $2+$ moderate/vigorous physical activity 
is linked to behavior-related risks when people are still at work. According to a survey comparing 10 European countries regarding how one spends time in everyday life, Finnish people had the longest reading time, whereas their TV viewing was moderate [29]. Conversely, as observed from the results of this study, the Japanese taste for TV viewing may be stronger than that of Finnish people. Therefore, in Japan, even older workers tend to spend their indoor leisure time on TV viewing, particularly if they have a low educational attainment. Because TV viewing further reduces individuals' energy expenditure compared with, e.g., reading as food and total energy intake is increased due to a tendency to eat while watching TV [3], there is a need for preventive measures to shorten the TV viewing especially among the older people with a low educational attainment in both countries.

A strength of this study is that it is based on harmonized variables from two large cohorts of the older people: one from Finland, a Scandinavian welfare state, and one from Japan, one of the world's highest longevity nation. However, this study also has several limitations. First, a sedentary lifestyle was indirectly evaluated by TV viewing time (including videos) based on self-reported questionnaires in the present studies. Other screen-time behaviors (e.g., computer and video games) and overall sitting time were not considered. Second, the question formats in each cohort differed for potential mediators, particularly moderate/vigorous PA. However, as further adjustment for PA had little effect on the observed associations, such heterogeneity is an unlikely source of major bias in the comparisons. Third, we used educational attainment as a measure of SES in both studies. A more comprehensive measurement of SES at an old age would also include income and occupational status, given that educational attainment is a determinant of future income and occupation [28]. Fourth, because we did not collect compatible variables of environmental factors between two cohorts, we only focused on individual factors. Previous studies have, however, reported that, for example, neighborhood poor walkability was associated with higher durations of daily TV viewing in adults $[21,30]$. Further investigation considering built environment factors are required. Finally, the data were cross-sectional. Although the time order between educational attainment and TV-viewing time at an old age is likely to be correct, the exposure and potential mediators were measured simultaneously.

\section{Conclusion}

Lower educational attainment was associated with highduration TV viewing, which is similar in Finland and Japan, particularly after retirement. This suggests a robust and consistent impact of educational attainment on a sedentary lifestyle after retirement.

\section{Additional file}

Additional file 1: Table S3. Association between educational attainment and TV viewing durations ( $\geq 3 \mathrm{~h}$ and $\geq 2 \mathrm{~h}$ per day) for each cohort and each current working status. The additional table presents the results of the sensitivity analyses with outcomes set to TV viewing durations of $\geq 3 \mathrm{~h}$ and $\geq 2 \mathrm{~h}$ per day. (XLSX $16 \mathrm{~kb}$ )

\section{Abbreviations}

BMI: Body mass index; Cl: Confidence interval; FPS: The Finnish Public Sector; JAGES: the Japan Gerontological Evaluation Study; PA: Physical activity; PR: Prevalence ratio; SES: Socioeconomic status; TV: Television

\section{Acknowledgements}

We would like to thank the study participants.

\section{Availability of data and material}

The data underlying this study are from the FPS study and the JAGES and contain sensitive information. Data for research purposes are available upon request. Requests for the FPS and the JAGES data can be made to kuntasektori@ttl.fi and dataadmin.ml@jages.net, respectively.

\section{Funding}

The FPS was supported by the participating organizations. SS was supported by the Academy of Finland and JP and JV by NordForsk, the Nordic Programme on Health and Welfare. The JAGES was supported by a grant of the Strategic Research Foundation Grant-aided Project for Private Universities from the Ministry of Education, Culture, Sport, Science, and Technology, Japan (MEXT), 2009-2013, for the Center for Well-being and Society, Nihon Fukushi University; a Health Labour Sciences Research Grant, Comprehensive Research on Aging and Health (H22-Choju-Shitei-008, H24-JunkankitouIppan-007, H24-Chikyukibo-Ippan-009, H24-Choju-Wakate-009, H25-KenkiWakate-015, H25-Irryo-Shitei-003 (Fukkou), H26-Choju-Ippan-006, H28-ChoujuIppan-02, H28-Ninchisho-Ippan-002) from the Japanese Ministry of Health, Labour and Welfare; JSPS KAKENHI $(22330172,22390400,23243070$, 23590786, 23790710, 24390469, 24530698, 24653150, 24683018, 25253052, 25870573, 25870881, 22390400, 15K18174, 15KT0007, 15H01972, 16K16595, 17K15822) from the Japan Society for the Promotion of Science; a grant from the National Center for Geriatrics and Gerontology (24-17, 24-23); the Research and Development Grants for Longevity Science from AMED; a grant from the Japan Foundation for Aging and Health; and also World Health Organization Centre for Health Development (WHO Kobe Centre) (WHO APW 2017/713981). The funding bodies played no role in study design, data collection and analysis, interpretation of data, and writing of the manuscript.

\section{Authors' contributions}

Conception and writing the article: $\Pi$; design: $\Pi$, AA, and KS; analysis and interpretation of the data: TT, SS, and JP; data collection: TO, JV and KK; critical revision of the article: AA, KS, SS, JP, TO, JV, and KK; principal investigator for the FPS: JV; and principal investigator for the JAGES: KK. All authors read and approved the final manuscript.

\section{Competing interest}

The authors have no conflict of interest to declare.

\section{Ethics approval and consent to participate}

The FPS study was approved by the Ethics Committee of the Helsinki and Uusimaa Hospital District. Answering to the FPS survey was voluntary and the completed questionnaire acted as an informed consent. The JAGES was by the Ethics Committee for Research on Human Subjects at Nihon Fukushi University, Japan (No. 10-05). JAGES participants were informed that participation in the study was voluntary and that completing and returning the questionnaire via mail indicated their consent to participate in the study.

Consent for publication

Not applicable. 


\section{Publisher's Note}

Springer Nature remains neutral with regard to jurisdictional claims in published maps and institutional affiliations.

\section{Author details}

${ }^{1}$ Center for Preventive Medical Sciences, Chiba University, 1-8-1 Inohana, Chuo Ward, Chiba City, Chiba, Japan. ${ }^{2}$ Department of Health Education and Health Sociology, School of Public Health, The University of Tokyo, 7-3-1 Hongo, Bunkyo Ward, Tokyo, Japan. ${ }^{3}$ Department of Public Health, Graduate School of Medicine, Osaka University, 2-2 Yamadaoka, Suita City, Osaka, Japan. ${ }^{4}$ Department of Public Health, University of Turku and Turku University Hospital, 20014 Turun yliopisto, Turku, Finland. ${ }^{5}$ Finnish Institute of Occupational Health, Topeliuksenkatu 41 b (Headquarters), 00250 Helsinki, Finland. ${ }^{6}$ Department of Gerontology and Evaluation Study, Center for Gerontology and Social Science, National Center for Geriatrics and Gerontology, 7-430 Morioka-cho, Obu City, Aichi, Japan.

Received: 27 March 2018 Accepted: 17 July 2018

Published online: 25 July 2018

\section{References}

1. Thorp AA, Owen N, Neuhaus M, Dunstan DW. Sedentary behaviors and subsequent health outcomes in adults a systematic review of longitudinal studies, 1996-2011. Am J Prev Med. 2011;41:207-15.

2. Boulos R, Vikre EK, Oppenheimer S, Chang H, Kanarek RB. ObesiTV: how television is influencing the obesity epidemic. Physiol Behav. 2012;107: 146-53.

3. Hu FB, Li TY, Colditz GA, Willett WC, Manson JE. Television watching and other sedentary behaviors in relation to risk of obesity and type 2 diabetes mellitus in women. JAMA. 2003;289:1785-91.

4. Ford ES, Schulze MB, Kroger J, Pischon T, Bergmann MM, Boeing $H$. Television watching and incident diabetes: findings from the European prospective investigation into Cancer and nutrition-Potsdam study. J Diabetes. 2010;2:23-7.

5. Ford ES, Caspersen CJ. Sedentary behaviour and cardiovascular disease: a review of prospective studies. Int J Epidemiol. 2012;41:1338-53.

6. Stamatakis E, Hamer M, Dunstan DW. Screen-based entertainment time, all-cause mortality, and cardiovascular events: population-based study with ongoing mortality and hospital events follow-up. J Am Coll Cardiol. 2011;57:292-9.

7. Howard RA, Freedman DM, Park Y, Hollenbeck A, Schatzkin A, Leitzmann MF. Physical activity, sedentary behavior, and the risk of colon and recta cancer in the NIH-AARP diet and health study. Cancer Causes Control. 2008; 19:939-53.

8. Gierach GL, Chang SC, Brinton LA, Lacey JV Jr, Hollenbeck AR, Schatzkin A, et al. Physical activity, sedentary behavior, and endometrial cancer risk in the NIH-AARP diet and health study. Int J Cancer. 2009;124:2139-47.

9. Wijndaele K, Brage S, Besson H, Khaw KT, Sharp SJ, Luben R, et al. Television viewing time independently predicts all-cause and cardiovascular mortality: the EPIC Norfolk study. Int J Epidemiol. 2011:40:150-9.

10. Sprod J, Ferrar K, Olds T, Maher C. Changes in sedentary behaviours across the retirement transition: a systematic review. Age Ageing. 2015;44:918-25

11. Flood SM, Moen P. Healthy time use in the encore years: do work, resources, relations, and gender matter? J Health Soc Behav. 2015;56:74-97.

12. Murakami K, Hashimoto H, Lee JS, Kawakubo K, Mori K, Akabayashi A. Distinct impact of education and income on habitual exercise: a crosssectional analysis in a rural city in Japan. Soc Sci Med. 2011;73:1683-8.

13. Wister AV. The effects of socioeconomic status on exercise and smoking: age-related differences. J Aging Health. 1996;8:467-88.

14. Grundy E, Holt G. The socioeconomic status of older adults: how should we measure it in studies of health inequalities? J Epidemiol Community Health. 2001;55:895-904.

15. Lahelma E, Martikainen $\mathrm{P}$, Laaksonen M, Aittomaki A. Pathways between socioeconomic determinants of health. J Epidemiol Community Health. 2004;58:327-32.

16. Biswas A, Oh PI, Faulkner GE, Bajaj RR, Silver MA, Mitchell MS, et al. Sedentary time and its association with risk for disease incidence, mortality, and hospitalization in adults: a systematic review and meta-analysis. Ann Intern Med. 2015;162:123-32.

17. Gebremariam MK, Altenburg TM, Lakerveld J, Andersen LF, Stronks K, Chinapaw MJ, et al. Associations between socioeconomic position and correlates of sedentary behaviour among youth: a systematic review. Obes Rev. 2015:16:988-1000

18. O'Donoghue G, Perchoux C, Mensah K, Lakerveld J, van der Ploeg H, Bernaards $C$, et al. A systematic review of correlates of sedentary behaviour in adults aged 18-65 years: a socio-ecological approach. BMC Public Health. 2016;16:163.

19. Stamatakis E, Grunseit AC, Coombs N, Ding D, Chau JY, Phongsavan P, et al. Associations between socio-economic position and sedentary behaviour in a large population sample of Australian middle and olderaged adults: the social, economic, and environmental factor (SEEF) study. Prev Med. 2014;63:72-80.

20. Stamatakis E, Coombs N, Rowlands A, Shelton N, Hillsdon M. Objectivelyassessed and self-reported sedentary time in relation to multiple socioeconomic status indicators among adults in England: a cross-sectional study. BMJ Open. 2014:4:e006034.

21. Kikuchi H, Inoue S, Sugiyama T, Owen N, Oka K, Shimomitsu T. Correlates of prolonged television viewing time in older Japanese men and women. BMC Public Health. 2013;13:213.

22. Chastin SF, Buck C, Freiberger E, Murphy M, Brug J, Cardon G, et al. Systematic literature review of determinants of sedentary behaviour in older adults: a DEDIPAC study. Int J Behav Nutr Phys Act. 2015;12:127.

23. Kondo K. Progress in aging epidemiology in Japan: the JAGES project. J Epidemiol. 2016;26:331-6.

24. Dunstan DW, Barr EL, Healy GN, Salmon J, Shaw JE, Balkau B, et al. Television viewing time and mortality: the Australian diabetes, obesity and lifestyle study (AusDiab). Circulation. 2010;121:384-91.

25. Goldberg DP, Gater R, Sartorius N, Ustun TB, Piccinelli M, Gureje O, et al. The validity of two versions of the GHQ in the WHO study of mental illness in general health care. Psychol Med. 1997;27:191-7

26. Alden D, Austin C, Sturgeon R. A correlation between the geriatric depression scale long and short forms. J Gerontol. 1989;44:P124-5.

27. Wada T, Ishine M, Kita T, Fujisawa M, Matsubayashi K. Depression screening of elderly community-dwelling Japanese. J Am Geriatr Soc. 2003:51:1328-9.

28. Glymour MM, Avendano M, Kawachi I. Socioeconomic status and health. In: Berkman LF, Kawachi I, Glymour MM, editors. Social Epidemiology Second Edition. New York, NY: Oxford University Press; 2014. p. 17-62.

29. European Communities. How Europeans spend their time - everyday life of women and men: data 1998-2002. Luxembourg: Office for Official Publications of the European Communities; 2004.

30. Sugiyama T, Salmon J, Dunstan DW, Bauman AE, Owen N. Neighborhood walkability and TV viewing time among Australian adults. Am J Prev Med. 2007:33:444-9.

\section{Ready to submit your research? Choose BMC and benefit from:}

- fast, convenient online submission

- thorough peer review by experienced researchers in your field

- rapid publication on acceptance

- support for research data, including large and complex data types

- gold Open Access which fosters wider collaboration and increased citations

- maximum visibility for your research: over $100 \mathrm{M}$ website views per year

At $\mathrm{BMC}$, research is always in progress.

Learn more biomedcentral.com/submissions 